\title{
Impact of donor, recipient and matching on survival after high emergency lung transplantation in France
}

\author{
Arnaud Roussel ${ }^{1,2}$, Edouard Sage ${ }^{3}$, Gilbert Massard ${ }^{4}$, Pascal-Alexandre Thomas $\mathbb{1}^{5}$, \\ Yves Castier ${ }^{1}$, Elie Fadel ${ }^{6}$, Françoise Le Pimpec-Barthes ${ }^{7}$, Jean-Michel Maury ${ }^{8}$, \\ Jacques Jougon ${ }^{9}$, Philippe Lacoste ${ }^{10}$, Johanna Claustre ${ }^{11}$, Marcel Dahan ${ }^{12}$, \\ Augustin Pirvu ${ }^{11}$, Adrien Tissot ${ }^{10}$, Matthieu Thumerel (109, Gabrielle Drevet ${ }^{8}$, \\ Ciprian Pricopi ${ }^{7}$, Jérôme Le Pavec ${ }^{6}$, Hervé Mal ${ }^{1}$, Xavier-Benoit D' Journo ${ }^{5}$, \\ Romain Kessler ${ }^{4}$, Antoine Roux ${ }^{3}$, Richard Dorent ${ }^{2}$, Gabriel Thabut $^{1}$ and \\ Pierre Mordant ${ }^{1}$ for the French Groups of Lung Transplantation
}

@ERSpublications

The results of this first exhaustive multicentre French national study suggest that adverse outcomes associated with high emergency lung transplantation are mainly related to the severity status of recipients rather than donor or matching characteristics http://bit.ly/2LSyWTE

Cite this article as: Roussel A, Sage E, Massard G, et al. Impact of donor, recipient and matching on survival after high emergency lung transplantation in France. Eur Respir J 2019; 54: 1900096 [https://doi. org/10.1183/13993003.00096-2019].

\section{ABSTRACT}

Introduction: Since July 2007, the French high emergency lung transplantation (HELT) allocation procedure prioritises available lung grafts to waiting patients with imminent risk of death. The relative impacts of donor, recipient and matching on the outcome following HELT remain unknown. We aimed at deciphering the relative impacts of donor, recipient and matching on the outcome following HELT in an exhaustive administrative database.

Methods: All lung transplantations performed in France were prospectively registered in an administrative database. We retrospectively reviewed the procedures performed between July 2007 and December 2015, and analysed the impact of donor, recipient and matching on overall survival after the HELT procedure by fitting marginal Cox models.

Results: During the study period, 2335 patients underwent lung transplantation in 11 French centres. After exclusion of patients with chronic obstructive pulmonary disease/emphysema, 1544 patients were included: 503 HELT and 1041 standard lung transplantation allocations. HELT was associated with a hazard ratio for death of 1.41 (95\% CI 1.22-1.64; $\mathrm{p}<0.0001)$ in univariate analysis, decreasing to $1.32(95 \%$ CI 1.10-1.60) after inclusion of recipient characteristics in a multivariate model. A donor score computed to predict long-term survival was significantly different between the HELT and standard lung transplantation groups $(\mathrm{p}=0.014)$. However, the addition of donor characteristics to recipient characteristics in the multivariate model did not change the hazard ratio associated with HELT.

Conclusions: This exhaustive French national study suggests that HELT is associated with an adverse outcome compared with regular allocation. This adverse outcome is mainly related to the severity status of the recipients rather than donor or matching characteristics. 


\section{Introduction}

The development of lung transplantation is currently limited by the availability of acceptable donor lungs. The imbalance between recipient demand and graft supply is still associated with a significant mortality on the waiting list $[1,2]$. Many strategies have been developed to increase the donor pool, including progressive extension of donor criteria, ex vivo assessment of marginal grafts and development of donation after circulatory death [3]. These strategies have permitted a substantial increase of available grafts without worsening recipient outcome $[4,5]$. Concomitantly, prioritisation systems have been developed to improve graft allocation to the sickest recipients. Prioritisation can be based on a recipient severity score applied to all patients, such as the lung allocation score (LAS) used in the USA and Germany [6-8], or on an emergency procedure to rescue only the sickest patients, such as the urgent procedures used in Italy and France $[9,10]$.

Specifically, the French procedure of high emergency lung transplantation (HELT) was implemented in 2007 to extract from the rotation list among centres and prioritise for graft allocation those patients whose life expectancy falls under 2 weeks. After an external assessment of recipient eligibility, the HELT procedure prioritises the allocation of any adult graft available on the national territory for 1 week, which can be extended to a second week. Over the past 10 years, crude analysis of the French lung transplant registry showed a decrease in waiting list mortality but also a decrease in post-transplant survival in HELT patients compared with non-HELT patients receiving standard lung transplantation [11]. Concomitantly, many retrospective series focusing on recipients yield conflicting results regarding the impact of HELT on post-transplant survival.

Aside from recipient severity status, the prognostic impact of HELT could be ascribed to the more frequent use of marginal or mismatched donors in the specific context of an urgent procedure. We aimed at deciphering the relative impacts of donor, recipient and matching on the outcome following HELT in an exhaustive administrative database.

\section{Methods}

\section{Study design}

We performed a retrospective study of a prospectively maintained national administrative database. We included recipients older than 12 years who received a lung transplantation between July 2007 and December 2015 in one of the 11 French lung transplantation centres. Data were prospectively recorded in the nationwide administrative database Cristal maintained by the French organ procurement organisation (OPO) Agence de la Biomédecine and retrospectively analysed. The study was approved by the Institutional Review Board of the French Thoracic and Cardiovascular Surgery Society, which waived the need for study-specific informed consent (CERC-SFCTCV-2016-3-23-16-35-3-MoPi), and by the French OPO Agence de la Biomédecine that provided the data. Study-specific authorisation was obtained from the coordinating physician of each of the 11 French lung transplantation centres. Patient consent to electronic record and scientific analysis of anonymous data was obtained at the time of listing in each centre.

\section{Data collection}

Recipient-related variables included age, sex, underlying disease, pre-operative use of mechanical ventilation and extracorporeal assistance, systolic and mean pulmonary arterial pressure, and body mass index (BMI). Donor-related variables included age, sex, smoking history and intensity, cause of death, arterial oxygen tension $\left(\mathrm{P}_{\mathrm{aO}_{2}}\right)$ /inspiratory oxygen fraction $\left(\mathrm{F}_{\mathrm{IO}_{2}}\right)$ ratio at the time of proposal (measured with $F_{\mathrm{IO}_{2}}$ of 1 and positive expiratory pressure of $5 \mathrm{cmH}_{2} \mathrm{O}$ ), ischaemic time and length of mechanical ventilation. Procedure-related variables included type of transplantation, intra-operative use of extracorporeal assistance, ABO blood group mismatch, cytomegalovirus (CMV) mismatch and size mismatch. Graft size was defined as the predicted total lung capacity (pTLC); size mismatch was defined as oversizing if the donor-to-recipient pTLC ratio was $>1.2$ and undersizing if the donor-to-recipient pTLC ratio was $<0.8[12]$.

Affiliations: ${ }^{1}$ Hôpital Bichat, Université Paris-Diderot, INSERM 1152, Paris, France. ${ }^{2}$ Agence de la Biomédecine, Saint Denis, France. ${ }^{3}$ Hôpital Foch, Université Versailles-Saint-Quentin, Suresnes, France. ${ }^{4}$ Nouvel Hôpital Civil, CHU de Strasbourg, Strasbourg, France. ${ }^{5}$ Hôpital Nord, CHU de Marseille, Marseille, France. ${ }^{6} \mathrm{Hôp}$ ital Marie-Lannelongue, Université Paris-Sud, Le Plessis Robinson, France. ${ }^{7}$ Hôpital Européen Georges-Pompidou, Université Paris-Descartes, Paris, France. ${ }^{8}$ Hôpital Louis-Pradel, CHU de Lyon, Lyon, France. ${ }^{9}$ Hôpital du Haut Lévèque, CHU de Bordeaux, Pessac, France. ${ }^{10}$ Hôpital Nord-Laennec, CHU de Nantes, Nantes, France. ${ }^{11}$ Hôpital Michallon, CHU de Grenoble, Grenoble, France. ${ }^{12}$ Hôpital Larrey, CHU de Toulouse, Toulouse, France.

Correspondence: Arnaud Roussel, AP-HP, Bichat Hospital, 46 rue Henri Huchard, 75018 Paris, France. E-mail: arnaudkiem.rousseldagmail.com 


\section{Allocation procedure}

Regular allocation is based on a rotation list among centres, with a priority based on administrative regions. The organ is allocated to a centre in which the team selects the most adequate recipient on the waiting list. For patients whose access to lung transplantation is expected to be restricted due to an uncommon blood group or anatomical considerations, a derogation may be issued by the French OPO Agence de la Biomédecine allowing the use of ABO-compatible donors.

HELT allocation was defined in July 2007, and the combined clinical and biological criteria are listed in table 1. Theoretically, only patients with pulmonary fibrosis, cystic fibrosis (CF) or pulmonary hypertension are eligible for HELT; patients with chronic obstructive pulmonary disease (COPD)/ emphysema are not. To be listed on the HELT list, patients have to be already listed on the regular lung transplantation list. Patients requiring mechanical ventilation or extracorporeal assistance are automatically listed on the HELT list. The request is evaluated and validated by two external experts. The HELT procedure gives a national priority for lung allocation for 8 days, with one renewal. Unlimited derogation can be allowed in selected cases.

For patients who do not fulfil the aforementioned criteria but are deemed critically ill by a transplantation team, a derogation can be allowed after examination by external experts, and a few patients with redo transplantation (included) and COPD/emphysema (excluded) might have benefited from the HELT procedure.

\section{Statistical methods}

Categorical data were expressed as number (percentage) and compared using the Chi-squared test. Continuous variables were expressed as mean with standard deviation and compared with the t-test. Missing covariate values were imputed using the multiple imputations by chained equations method, which resulted in five imputed data sets. Missing data were assumed to be data missing at random or missing completely at random. Each of the five data sets was analysed independently. Estimates of the variables were averaged according to the Rubin rules.

The primary outcome was overall survival time following transplantation, defined as the time interval between the date of operation and the date of death or the last follow-up visit for censored patients. The follow-up was complete for all patients. Median (interquartile range) follow-up was 39.3 (19.8-64.3) months. Overall survival was estimated by the Kaplan-Meier estimator and compared with the log-rank test.

We used Cox proportional hazards regression models to assess variables associated with overall survival following lung transplantation. All variables with $\mathrm{p}<0.2$ in univariate analysis as well as variables known to be associated with the outcomes in the literature were included in the models. Because HELT is available only for patients with the most severe health status, only recipient characteristics not part of the criteria for HELT were included in the multivariable models. Within-centre correlations were accounted for using the marginal Cox model, in which the variance is estimated by a grouped jackknife procedure [13].

To assess whether the effect of HELT was constant over time (proportional hazards assumption), we used a smoothing of the scaled Schoenfeld residuals plots [14]. The relationships between recipient and donor characteristics (continuous variables) with the relative risk of death and the scale of the continuous covariates were estimated by fitting regression splines.

\begin{tabular}{|c|c|c|c|}
\hline & Cystic fibrosis & Pulmonary fibrosis & Pulmonary hypertension \\
\hline $\begin{array}{l}\text { Inclusion } \\
\text { criteria }\end{array}$ & $\begin{array}{l}\text { Invasive } \\
\text { mechanical } \\
\text { ventilation }\end{array}$ & $\begin{array}{l}\text { Invasive mechanical } \\
\text { ventilation }\end{array}$ & Invasive mechanical ventilation \\
\hline Or & ECMO & ECMO & ECMO \\
\hline Or & $\begin{array}{l}P_{\mathrm{aCO}_{2}}>80 \mathrm{mmHg} \\
\text { and NIV }>18 / 24 \mathrm{~h} \\
\quad \text { for } 72 \mathrm{~h}\end{array}$ & $\begin{array}{l}\mathrm{S}_{\mathrm{aO}_{2}}<90 \% \text { despite high } \\
\text { concentration oxygen therapy } \\
\text { and maximal medical } \\
\text { treatment }\end{array}$ & $\begin{array}{l}\text { NYHA class IV and cardiac index } \\
<2 \mathrm{~L} \cdot \mathrm{min}^{-1} \text { and PVR }>1200 \text { dyn } \cdot \mathrm{s} \cdot \mathrm{cm}^{-3} \\
\text { and maximal medical treatment for } \\
72 \mathrm{~h}\end{array}$ \\
\hline $\begin{array}{r}\text { Exclusion } \\
\text { criteria }\end{array}$ & \multicolumn{3}{|c|}{$\begin{array}{l}\text { Clinical statement not compatible with surgery: haemodynamic or multiorgan failure or } \\
\text { uncontrolled sepsis } \\
\text { Aetiology: chronic obstructive pulmonary disease, emphysema, retransplantation }\end{array}$} \\
\hline
\end{tabular}

ECMO: extracorporeal membrane oxygenation; $P_{\mathrm{aCO}}$ : arterial carbon dioxide tension; NIV: noninvasive ventilation; $\mathrm{S}_{\mathrm{aO}}$ : arterial oxygen saturation; NYHA: New York Heart Association; PVR: pulmonary vascular resistance. 
To explore the sensitivity of our results, we repeated the analyses across a range of different models. We restricted the analysis by adjusting only on covariates with $<10 \%$ of missing data. We also modelled centre using a mixed effect Cox model, which assumes that the centre effect follows a normal distribution with a mean of 0 . The random effect for a given centre represents the deviation of this centre from the overall underlying baseline risk.

Analyses were performed using R version 3.2.1 (R Foundation for Statistical Computing, Vienna, Austria). The marginal Cox model for survival involved use of the coxph function (survival package) with the cluster option, while the mixed effect model involved the use of the coxph function with the frailty option.

\section{Results}

\section{Study group}

During the study period, 2328 patients underwent lung transplantation in France, including 784 (34\%) patients with COPD/emphysema who were excluded from the analysis (the characteristics and outcomes of the COPD/emphysema patients are summarised in supplementary tables S1 and S2, and supplementary figure S1). Thus, 1544 patients were included in the analysis and accounted for the study group. The number of patients undergoing lung transplantation in each centre ranged between 102 and 412. 503 transplantations (33\%) were performed following a high emergency allocation of the lung graft and accounted for the HELT group. The evolution of the number of patients undergoing lung transplantation during the study period and the number of HELT procedures are shown in figure 1 . The main characteristics of donors, recipients and procedures are summarised in table 2 and supplementary table S3. The overall mean \pm SD waiting time was $23 \pm 39$ months. The mean \pm SD waiting time was $6.4 \pm 5.4$ days in the HELT group and $24 \pm 36$ months in the standard lung transplantation group.

\section{Comparison of baseline characteristics of the HELT and standard lung transplantation (non-HELT)} groups

As shown in the comparison between HELT and standard lung transplantation groups for donor, recipient and surgery characteristics in table 2, recipient characteristics differed significantly between groups, with a

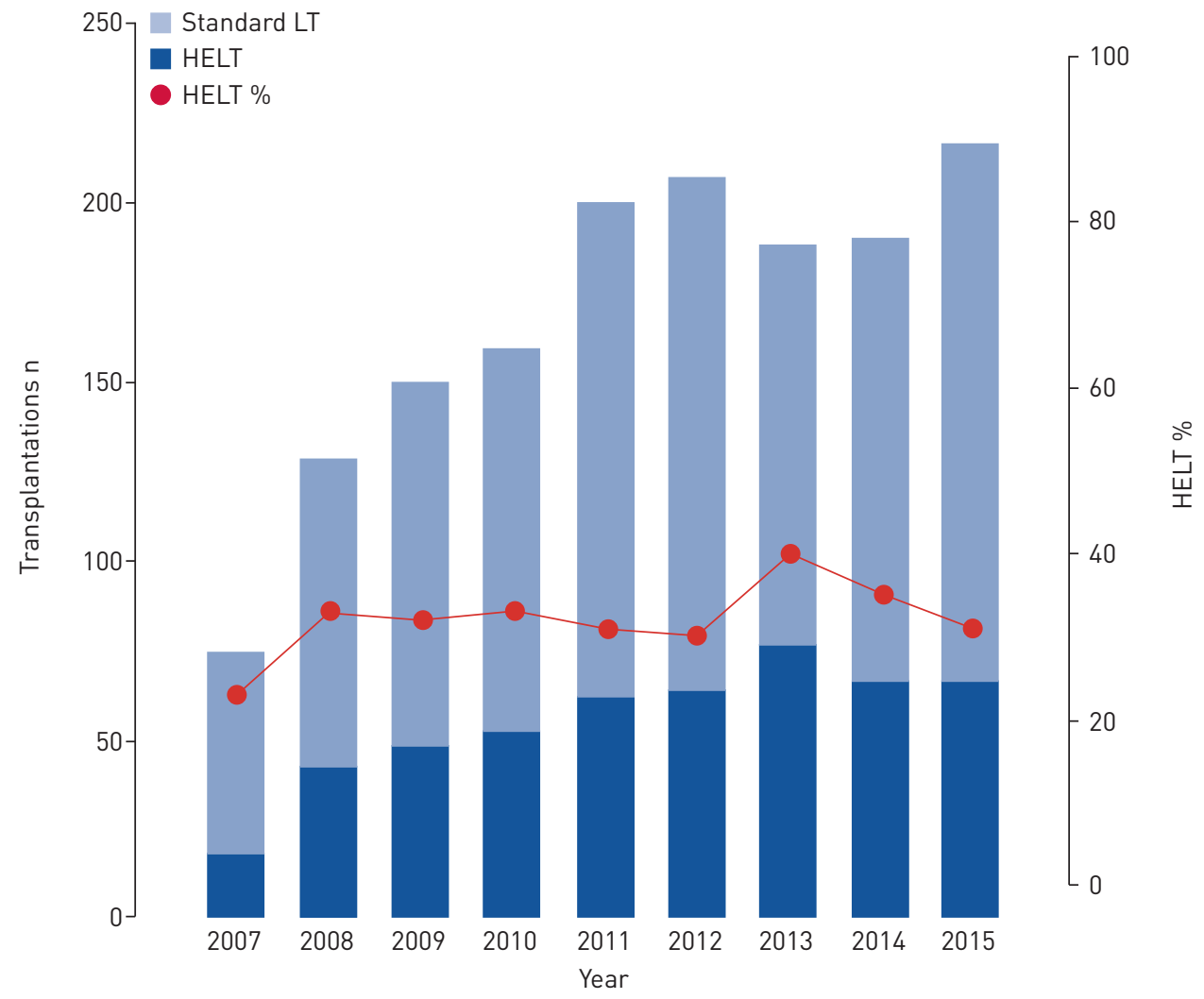

FIGURE 1 Evolution of the number of patients undergoing lung transplantation (LT) and the number of high emergency lung transplantations (HELTs) between July 2007 and December 2015 in France (chronic obstructive pulmonary disease excluded). 
TABLE 2 Comparison of characteristics of donors, recipients and surgical procedure according to the type of procedure: high emergency lung transplantation (HELT) and standard lung transplantation (LT)

\begin{tabular}{|c|c|c|c|c|}
\hline & Patients & HELT & Standard LT & p-value \\
\hline Subjects & 1544 & 503 & 1041 & \\
\hline \multicolumn{5}{|l|}{ Donors } \\
\hline Age years & $43.7 \pm 15.5$ & $44.3 \pm 15.1$ & $43.5 \pm 15.7$ & 0.35 \\
\hline Male & $843(55)$ & $267(53)$ & $576(55)$ & 0.41 \\
\hline Smoking history & 599 (39) & $187(37)$ & $412(40)$ & 0.36 \\
\hline Smoking intensity pack-years & $6.4 \pm 11.8$ & $5.9 \pm 11.2$ & $6.6 \pm 12.1$ & 0.26 \\
\hline Body mass index $\mathrm{kg} \cdot \mathrm{m}^{-2}$ & $24.0 \pm 4.1$ & $24.1 \pm 4.1$ & $24.0 \pm 4.1$ & 0.70 \\
\hline Cause of death & & & & 0.87 \\
\hline Vascular & $843(55)$ & $278(55)$ & $565(54)$ & \\
\hline Traumatic & $450(29)$ & 149 (30) & 301 (29) & \\
\hline Anoxia & 185 (12) & $56(11)$ & 129 (13) & \\
\hline Other ${ }^{\#}$ & $66(4)$ & $20(4)$ & $46(4)$ & \\
\hline Length of mechanical ventilation days & $2.56 \pm 2.46$ & $2.55 \pm 2.69$ & $2.57 \pm 2.33$ & 0.93 \\
\hline$P_{\mathrm{aO}}$ before harvest $\mathrm{mmHg}$ & $409.1 \pm 92.0$ & $416.4 \pm 89.7$ & $405.6 \pm 93.0$ & 0.031 \\
\hline$P_{\mathrm{aO}_{2}}$ before harvest according to two groups & & & & 0.086 \\
\hline$\geqslant 350 \mathrm{mmHg}$ & $1171(76)$ & 395 (79) & $776(75)$ & \\
\hline$<350 \mathrm{mmHg}$ & $373(24)$ & $108(21)$ & $265(25)$ & \\
\hline Predicted TLC L & $6.04 \pm 1.11$ & $6.01 \pm 1.08$ & $6.06 \pm 1.13$ & 0.36 \\
\hline \multicolumn{5}{|l|}{ Recipients } \\
\hline Age years & $40.2 \pm 15.5$ & $37.4 \pm 15.2$ & $41.6 \pm 15.5$ & $<0.0001$ \\
\hline Male & $843(55)$ & $265(53)$ & $578(56)$ & 0.29 \\
\hline Body mass index $\mathrm{kg} \cdot \mathrm{m}^{-2}$ & $21.4 \pm 4.9$ & $20.7 \pm 4.6$ & $21.7 \pm 5.0$ & 0.00012 \\
\hline Diabetes & $423(27)$ & $139(29)$ & $284(29)$ & 0.82 \\
\hline Systolic PAP mmHg & $46.4 \pm 23.2$ & $52.3 \pm 26.0$ & $44.1 \pm 21.6$ & 0.00036 \\
\hline Mean PAP $\mathrm{mmHg}$ & $25.4 \pm 15.2$ & $29.7 \pm 17.5$ & $23.6 \pm 13.8$ & $<0.0001$ \\
\hline Mean PAP according to two groups & & & & 0.017 \\
\hline$>25 \mathrm{mmHg}$ & 201 (13) & 72 (45) & 129 (34) & \\
\hline$\leqslant 25 \mathrm{mmHg}$ & $341(22)$ & 89 (55) & $252(66)$ & \\
\hline Actual TLC \% pred & $83 \pm 33$ & $77.7 \pm 31.7$ & $85.3 \pm 33.0$ & 0.0068 \\
\hline Predicted TLC L & $5.79 \pm 1.12$ & $5.71 \pm 1.15$ & $5.83 \pm 1.11$ & 0.060 \\
\hline Size mismatch & $471(31)$ & $176(35)$ & $295(28)$ & 0.0078 \\
\hline Oversized & $327(70)$ & $121(69)$ & $206(70)$ & \\
\hline Undersized & $144(30)$ & $55(31)$ & $89(30)$ & \\
\hline Underlying disease & & & & $<0.0001$ \\
\hline Bronchiectasis/cystic fibrosis & $745(48)$ & $235(47)$ & 510 (49) & \\
\hline Fibrosis & 499 (32) & 166 (33) & 333 (32) & \\
\hline Pulmonary hypertension & $119(8)$ & $61(12)$ & $58(6)$ & \\
\hline Redo transplantation & $34(2)$ & $12(2)$ & $22(2)$ & \\
\hline Other ${ }^{n}$ & $147(10)$ & $29(6)$ & $118(11)$ & \\
\hline Support before transplantation & & & & $<0.0001$ \\
\hline No support & $787(51)$ & $146(49)$ & $641(62)$ & \\
\hline Mechanical ventilation only & 506 (33) & 115 (39) & $391(38)$ & \\
\hline Cardiopulmonary only & $12(1)$ & $12(4)$ & $0(0)$ & \\
\hline Mechanical ventilation and cardiopulmonary & $25(2)$ & $25(8)$ & $0(0)$ & \\
\hline Pre-operative cardiopulmonary support & $38(2)$ & $38(13)$ & $0(0)$ & $<0.0001$ \\
\hline \multicolumn{5}{|l|}{ Surgical procedure } \\
\hline Type of transplantation & & & & 0.034 \\
\hline Double lung & $1147(74)$ & $379(75)$ & $768(74)$ & \\
\hline Single lung & $304(20)$ & 85 (17) & $219(21)$ & \\
\hline Other (lobar, bilobar, bipartition) & $93(6)$ & $39(8)$ & $54(5)$ & \\
\hline Intra-operative cardiopulmonary support & $762(49)$ & $354(72)$ & $408(40)$ & $<0.0001$ \\
\hline Ischaemic time min & $371.7 \pm 108.6$ & $358.9 \pm 88.7$ & $378.2 \pm 116.8$ & 0.015 \\
\hline Blood group mismatch & $139(9)$ & $121(24)$ & $18(2)$ & $<0.0001$ \\
\hline CMV mismatch & $343(22)$ & $118(24)$ & $225(22)$ & 0.36 \\
\hline Post-operative cardiopulmonary support & $301(19)$ & 127 (39) & $174(26)$ & $<0.0001$ \\
\hline
\end{tabular}

Data are presented as $\mathrm{n}(\%)$ or mean $\pm \mathrm{SD}$, unless otherwise stated. $P_{\mathrm{aO}_{2}}$ : arterial oxygen tension; TLC: total lung capacity; PAP: pulmonary arterial pressure; CMV: cytomegalovirus. " : other causes of death include intoxication, meningitis and tumour; ": other underlying diseases include Eisenmenger syndrome, Langherans cell histiocytosis, other congenital disease, toxic cause and sarcoidosis. 
younger age $(37.4 \pm 15.2$ versus $41.6 \pm 15.5$ years; $\mathrm{p}<0.0001)$, a higher mean pulmonary arterial pressure $(29.7$ \pm 17.5 versus $23.6 \pm 13.8 \mathrm{mmHg} ; \mathrm{p}<0.0001)$ and a higher proportion of pulmonary hypertension $(12 \%$ versus $6 \% ; \mathrm{p}<0.0001$ ) in the HELT group compared with the standard lung transplantation group. Interestingly, donor characteristics did not differ significantly between groups, except for $P_{\mathrm{aO}}$ before harvest with a slightly higher mean $P_{\mathrm{aO}_{2}}$ in the HELT group $(416.4 \pm 89.7$ versus $405.6 \pm 93.0 \mathrm{mmHg} ; \mathrm{p}=0.031)$.

Blood group mismatch $(24 \%$ versus $2 \%$; $\mathrm{p}<0.0001)$ and size mismatch $(35 \%$ versus $28 \%$; $\mathrm{p}=0.0078)$ were more frequent in the HELT group than in the standard lung transplantation group. A subgroup analysis of the 653 patients (42\% of the study group) with actual TLC (aTLC) nonmissing data was performed. The mean \pm SD recipient aTLC was $4.82 \pm 2.0 \mathrm{~L}$ and the mean \pm SD donor pTLC was $5.97 \pm 1.1 \mathrm{~L}$, resulting in 413 (63\% of available aTLC) size mismatches: $35 \%$ in the HELT group versus $28 \%$ in the standard lung transplantation group $(\mathrm{p}=0.0078)$. Size mismatch characteristics according to the underlying diseases and allocation procedure are summarised in table 3.

Comparison of donor, recipient and matching characteristics was also performed in a subgroup analysis according to the underlying diagnosis, as shown in supplementary tables S4-S6. In the CF subgroup, HELT patients underwent more lobar and split lung transplantations and less regular double lung transplantation (DLT) than standard lung transplantation patients (9\% lobar and split lung and $89 \%$ regular DLT in HELT versus 6\% lobar and split lung and 93\% regular DLT in standard lung transplantation; $\mathrm{p}=0.057$ ). In the pulmonary fibrosis subgroup, HELT patients underwent more DLT and less single lung transplantation (SLT) than standard lung transplantation patients (51\% DLT and 40\% SLT in HELT versus $41 \%$ DLT and 53\% SLT in standard lung transplantation; $\mathrm{p}=0.031$ ).

\section{Impact of HELT on overall survival}

The median survival was 76.0 months for the study group, with a significant difference between the HELT and standard lung transplantation groups (53.2 versus 79.0 months; $\mathrm{p}<0.0001$ ) (figure 2). In univariate analysis accounting for within-centre correlations, HELT was associated with a hazard ratio for death of 1.41 (95\% CI 1.22-1.64; $\mathrm{p}<0.0001)$. The same increase in the instantaneous risk of death was found whatever the indication for lung transplantation, with a hazard ratio of 1.47 (95\% CI 1.12-1.92), 1.46 (95\% CI 1.19-1.79) and 1.62 (95\% CI 1.08-2.46) in the CF, pulmonary fibrosis and pulmonary hypertension groups, respectively, and no significant interaction between HELT and underlying diagnosis. Tests of the analyses' proportional hazards assumptions with residual plots suggest an increased relative risk of death in the HELT group during the early post-operative period, which vanishes over the first 3 years. We confirmed these findings with a separate analysis of hazard ratios according to four post-operative periods, as shown in figure 3 and supplementary table S7. In pulmonary hypertension patients, the increase in the instantaneous risk of death associated with HELT was not statistically significant when post-operative periods were considered separately.

Other factors associated with long-term survival (univariate analysis)

In univariate analysis, among donor-related variables, age and smoking intensity were significantly associated with long-term survival. Among recipient-related variables, age, BMI, type of transplantation

TABLE 3 Size mismatch characteristics according to the underlying diseases and allocation procedure in the high emergency lung transplantation (HELT) and standard lung transplantation (LT) groups

\begin{tabular}{|c|c|c|c|c|c|c|c|c|}
\hline & \multicolumn{2}{|c|}{ Cystic fibrosis ${ }^{\#}$} & \multicolumn{2}{|c|}{$\begin{array}{l}\text { Pulmonary } \\
\text { fibrosis }^{\pi}\end{array}$} & \multicolumn{2}{|c|}{$\begin{array}{c}\text { Pulmonary } \\
\text { hypertension }\end{array}$} & \multicolumn{2}{|r|}{ Other $\S$} \\
\hline & HELT & Standard LT & HELT & Standard LT & HELT & Standard LT & HELT & Standard LT \\
\hline Subjects & 71 & 189 & 82 & 165 & 26 & 33 & 13 & 74 \\
\hline No mismatch & \multicolumn{2}{|r|}{154 (59) } & \multicolumn{2}{|r|}{$24(10)$} & \multicolumn{2}{|r|}{$32(54)$} & \multicolumn{2}{|r|}{$30(34)$} \\
\hline Oversizing & 44 & $67(26)$ & 6 & $\begin{array}{c}18 \\
20(89)\end{array}$ & 11 & $20(34)^{21}$ & 3 & $44(51)^{27}$ \\
\hline \multirow{2}{*}{ Undersizing } & 19 & $39(15)^{48}$ & 76 & $3(1)^{144}$ & 12 & $7(12)^{8}$ & 8 & $13(15)^{36}$ \\
\hline & 8 & 31 & 0 & 3 & 3 & 4 & 2 & 11 \\
\hline
\end{tabular}

Data are given as $n$ or $n(\%) .{ }^{\#}: n=260 ; ~_{\text {n: }} \mathrm{n}=247 ;{ }^{+}: \mathrm{n}=59 ;{ }^{\S}: \mathrm{n}=87$ lother underlying diseases include Eisenmenger syndrome, Langherans cell histiocytosis, other congenital disease, toxic cause, sarcoidosis and redo transplantation). 


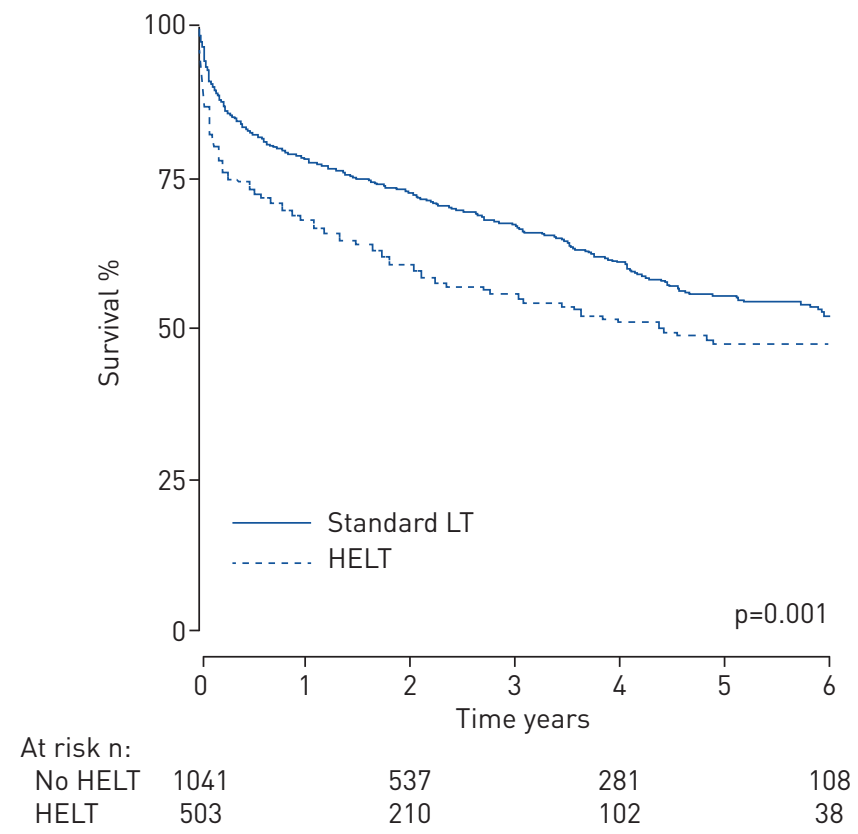

FIGURE 2 Kaplan-Meier estimates for survival after transplantation according to the type of procedure: high emergency lung transplantation (HELT) and standard lung transplantation (LT).

and intra-operative cardiopulmonary support were significantly associated with long-term survival. Mismatches in the blood group and CMV were significantly associated with long-term survival. Relationships between continuous recipient and donor characteristics and the relative risk of death

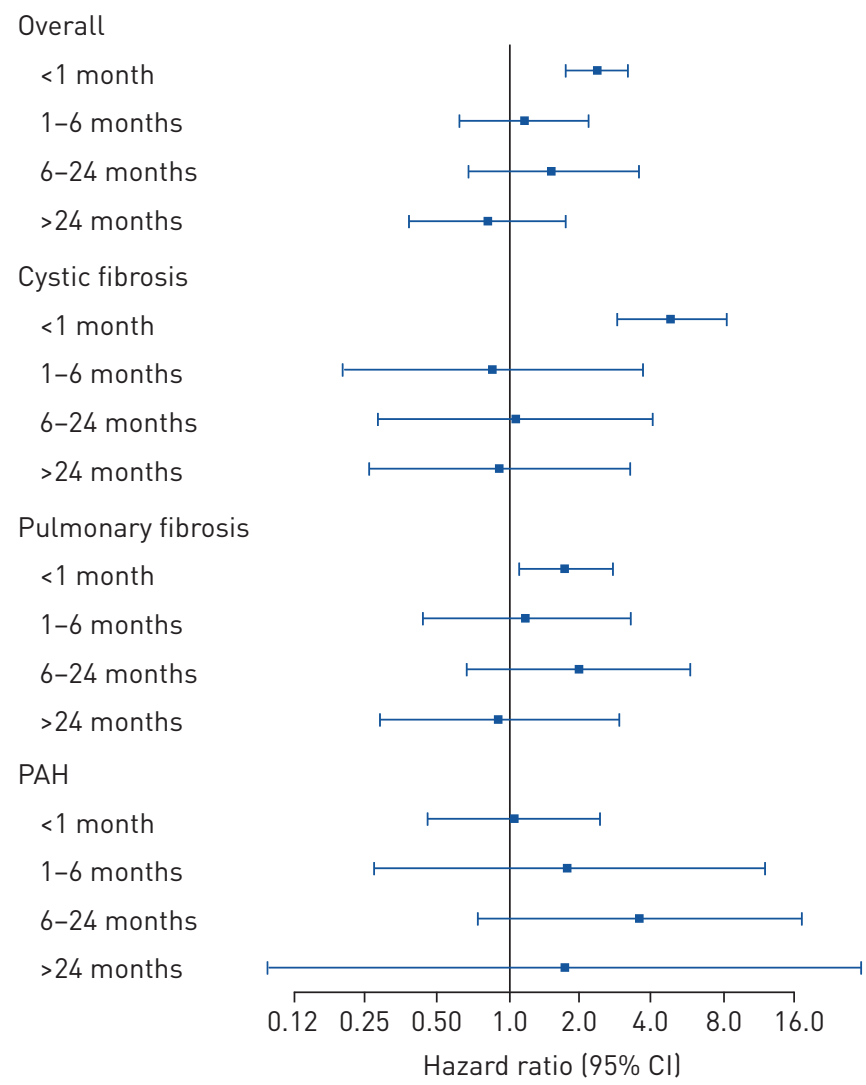

FIGURE 3 Hazard ratio (95\% CI) according to four post-operative periods and indications. PAH: pulmonary arterial hypertension. 
estimated by fitting regression splines are displayed in supplementary figures S2 and S3. These models suggest nonlinear relationships between recipient age, recipient BMI, size mismatch, TLC mismatch and $\log$ hazard for death.

\section{Factors associated with long-term survival (multivariate analysis)}

Inclusion of recipient characteristics in a Cox model reduces the hazard ratio for HELT from 1.47 to 1.32 (95\% CI 1.10-1.59). Inclusion of recipient and donor characteristics in the model did not change the hazard ratio associated with HELT in comparison with the model including the recipient characteristics only (1.32 (95\% CI 1.10-1.60)). To further assess the impact of donor characteristics on post-operative survival, we computed a donor score based on the linear combination of variables pertaining to the donors from these models. Variables included in the donor score were donor characteristics (age, sex, smoking history, smoking intensity, $\mathrm{BMI}, \mathrm{P}_{\mathrm{aO}}$ before harvest and length of mechanical ventilation) and matching characteristics (size mismatch, blood group mismatch and CMV mismatch). Higher donor scores indicate lower expected survival after lung transplantation, with individual scores ranging from -0.21 to 1.31 . The mean \pm SD donor scores significantly differed between the HELT and standard lung transplantation groups $(0.27 \pm 0.17$ versus $0.24 \pm 0.17 ; \mathrm{p}=0.014)$, indicating that patients undergoing HELT were given donors with a slightly higher hazard of death. This difference reflects an increase of the instantaneous risk of death of $4.2 \%$. The donor scores according to centre and HELT using one of the five imputed data sets are shown in figure 4.

\section{Sensitivity analyses}

To explore the sensitivity of our findings to different assumptions, we repeated the analyses across a range of model specifications. The results remained unchanged by using a mixed effect Cox model or adjusting on a different set of covariates by removing those with $>10 \%$ of missing data.

\section{Discussion}

\section{Summary of the main results}

Studying the impact of donor, recipient and matching on long-term outcome following HELT in France, we found that 1) the HELT procedure was associated with an increased instantaneous risk of death whatever the underlying diagnosis; 2) donor $P_{\mathrm{aO}}, \mathrm{ABO}$ mismatch and size mismatch differed between the

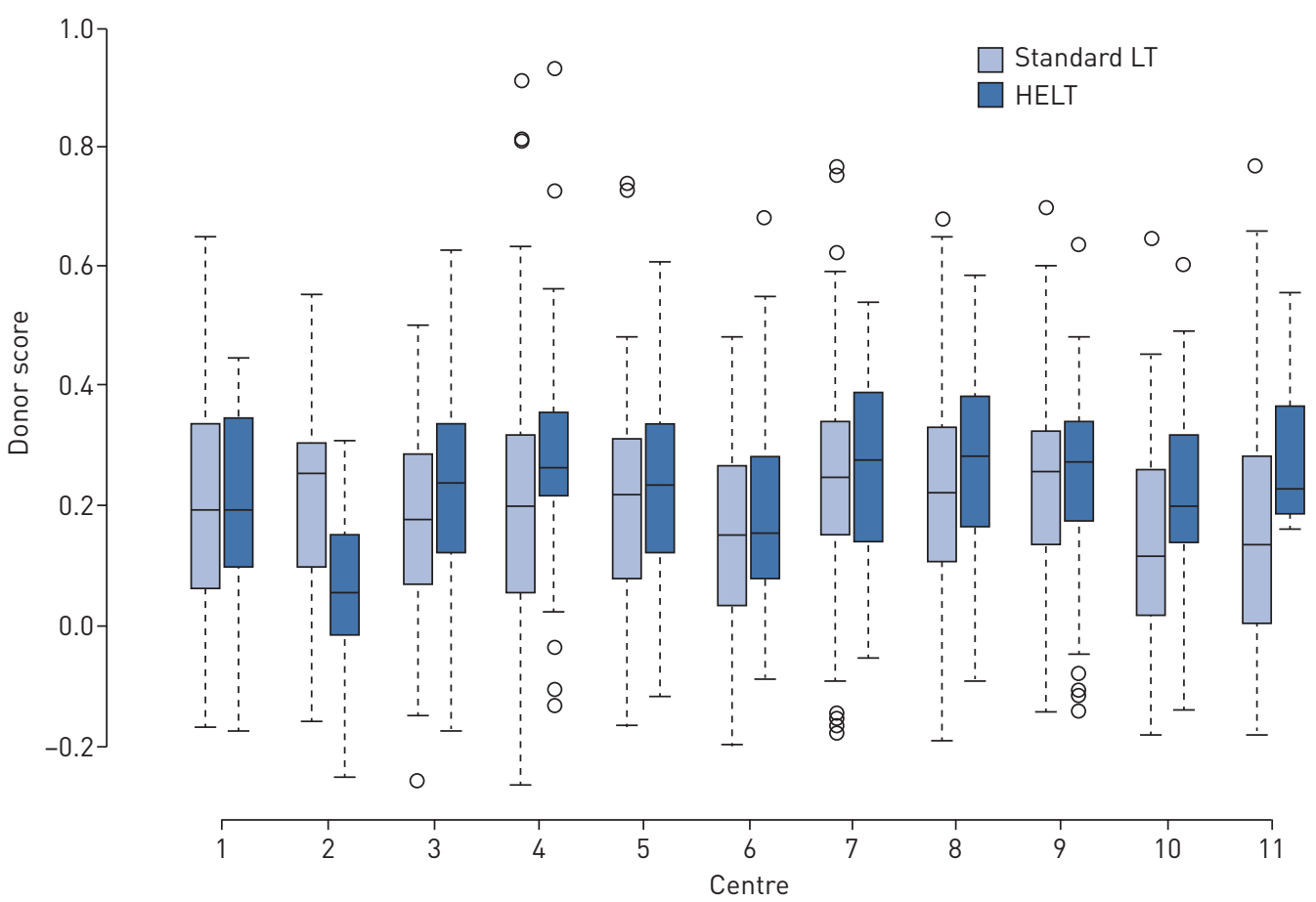

FIGURE 4 Donor score according to centre and type of procedure: high emergency lung transplantation (HELT) and standard lung transplantation (LT) using one imputed data set. Data are presented as median and second and third interquartile ranges (IQRs) (boxes) with first and fourth IQRs (whiskers); outliers are indicated as open circles. 
HELT and standard lung transplantation groups; and 3) the adverse outcome associated with the HELT procedure was mainly related to the severity status of the recipients rather than donor or matching.

\section{Waiting list and post-transplant outcome}

The French lung allocation system is based on a rotational list that was historically associated with significant mortality during the waiting period, especially for idiopathic pulmonary fibrosis patients [15]. Introduced in 2007, the French HELT procedure has been designed to minimise mortality on the waiting list by rescuing the sickest patients through the allocation of any graft available on the national territory for 2 weeks, but its implications for graft utilisation and long-term outcome had not been anticipated. The French HELT allocation is indeed an effective strategy to reduce mortality on the waiting list as demonstrated in previous studies [16-18]. Waiting list data were not available for this study, but the 2017 Annual Report of the French OPO Agence de la Biomédecine showed a decrease of the cumulative incidence of death on the waiting list by taking into account the competing risk of transplantation from 1995 to 2017 (from $12 \%$ to $3 \%$ at 3 months post-registration and from $22 \%$ to $5 \%$ at 1 year post-registration) [19]. However, this cumulative incidence of death on the waiting list by taking into account the competing risk of transplantation was still higher in HELT patients than in standard lung transplantation patients ( $7 \%$ versus $3 \%$ at 3 months post-registration and $9 \%$ versus $6 \%$ at 1 year post-registration, respectively, between 2012 and 2017) [19].

Since the implementation of HELT in France, two multicentric studies showed a significantly lower survival in HELT compared with standard lung transplantation patients, even though survival rates after HELT were improving over time, from $51 \%$ at 2 years in 2012 ( $\mathrm{n}=32$ patients) to $59 \%$ at 3 years in 2014 $(\mathrm{n}=95$ patients) $[9,16]$. Unfortunately, these studies were based on retrospective questionnaires and were not exhaustive. Two unicentric studies focusing on certain diagnoses and a longer timespan found no significant difference between HELT and standard lung transplantation in CF patients, with 2-year survival rates of $73 \%$ and $75 \%$, respectively $(\mathrm{n}=201 ; \mathrm{p}=0.128)$, nor in pulmonary hypertension, with 5-year survival rates of $50 \%$ and $72 \%$, respectively $(n=234 ; \mathrm{p}=0.053)[17,18]$. These studies were exhaustive, but might have lacked statistical power to allow adequate comparisons. Conversely, we found the HELT procedure to be associated with an increased instantaneous risk of death and a high rate of prolonged extracorporeal membrane oxygenation (ECMO) post-transplant, whatever the indication for lung transplantation. This adverse outcome is of particular concern given the relatively low proportion of mechanical ventilation/ ECMO patients. A recent simulation study suggested that HELT should maintain a limited impact on the regular waiting list given that the graft supply is adequate [20]. Albeit beneficial to the sickest patients, the impact of HELT on long-term outcome is detrimental and its impact on lung utilisation should be assessed carefully.

\section{Donor and matching}

Whether the national priority could affect the quality of allocated grafts and matching was unclear before this study [18], with two hypotheses. On the one hand, as the lung pool is divided between 11 centres without HELT and directed toward one patient with HELT, the national priority could bias graft allocation toward offering better grafts to HELT compared with non-HELT patients (i.e. matching the best grafts to the sickest patients). On the other hand, the emergency situation might lead transplant physicians to decrease the threshold to accept a graft, because of the fear that no other graft will be available in the following days (i.e. matching the worst grafts to the sickest patients). Interestingly, we found that lung grafts accepted through the HELT procedure were similar to those accepted through the regular allocation procedure, except for a small difference in the mean $P_{\mathrm{aO}}$ before harvest. Donor $P_{\mathrm{aO}_{2}} / F_{\mathrm{IO}_{2}}$ ratio is known to be associated with early gas exchange and mortality after lung transplantation, and although it is debated, the threshold of $350 \mathrm{mmHg}$ is commonly accepted [21]. The difference between HELT and standard lung transplantation grafts has therefore limited clinical implications, as the proportion of patients with $P_{\mathrm{aO}}<350 \mathrm{mmHg}$ remains similar between groups. Even if the donor score was significantly different between the HELT and standard lung transplantation groups, its prognostic impact remains limited.

There were more $\mathrm{ABO}$ mismatches in the HELT than in the standard lung transplantation group. However, $\mathrm{ABO}$-compatible and $\mathrm{ABO}$-identical lung transplantations have been reported to be associated with a similar prognosis in a large study of 6655 lung transplantations included in the United Network for Organ Sharing (UNOS) database between 2005 and 2011 [22]. The prognostic impact of size mismatches between donor and recipient is more difficult to analyse, as definition and indication varied across studies. EBERLEIN et al. [23] studied the Lung Transplant Outcome Group database, defining oversizing as a donor-to-recipient pTLC ratio $>1.0$, and found that patients undergoing bilateral lung transplantation with oversized lungs experienced improved survival, an effect that appears most apparent in non-COPD patients. Conversely, a recent analysis of the UNOS database focusing on restrictive lung disease found 
that moderate oversizing, defined as a donor-to-recipient pTLC ratio between 1.1 and 1.2, was associated with an adverse prognosis [24]. Similarly, recipients of undersized allografts, defined by EBERLEIN et al. [23] as a donor-to-recipient pTLC ratio $\leqslant 1$, were more likely to experience primary graft dysfunction, tracheostomy and had higher resource utilisation [25]. Following International Society for Heart and Lung Transplantation guidelines [26], we defined size mismatch as oversizing if the donor-to-recipient pTLC ratio was $>1.2$ and as undersizing if the donor-to-recipient predicted TLC ratio was $<0.8$, and found it did not affect overall survival in the frame of the HELT procedure. Taken together, our data suggest that the adverse outcome associated with HELT is associated with recipient severity status, but not with donor or matching.

\section{Allocation policy}

Transplantation is the only medical therapy in which there is a life-sustaining therapy that is in short supply relative to the need [27], making allocation policy a critical point from both the individual and the population perspective. The main ethical principles associated with organ allocation include equity to eliminate bias or discrimination, justice to render each individual what is due to him/her and beneficence to expect a greater good over harm for the patient, but also utility to make the best use of a limited resource $[27,28]$. The relative weights of theses principles differ between countries. In particular, the principle of utility implies scaling up from the patient-physician relationship to a population level and might be difficult to balance with the first three principles from a physician perspective. The lung allocation system is a direct reflection of the public investment into ethical considerations.

Besides France, other countries have chosen to prioritise patients based on their gravity only, and therefore to allocate lungs based on urgency and not transplant benefit. The Scandiatransplant (Denmark, Estonia, Finland, Iceland, Norway and Sweden) urgent lung allocation system (ScULAS) was implemented in 2009, giving a supranational priority to patients considered urgent [29]. No predefined criteria for listing a patient as urgent are required, but Priority 0 includes patients on extracorporeal support or mechanical ventilation, and Priority 1 includes patients not on life support but with a rapid progression of lung failure and poor short-term prognosis as defined by the responsible centre. However, only three urgent calls per year are granted for each centre. Therefore, patients on life support might not benefit from an urgent status. Since the implementation of ScULAS, 30-day graft survival and 90-day graft survival have been significantly lower among patients listed as urgent, but there was no difference in 1-year graft survival. However, 81 patients were on life support and among them, only 39 patients were listed as urgent and 15 patients (19\%) died on the waiting list (five patients listed as urgent status and 10 patients listed as regular status). Moreover, graft survival was found to be significantly lower in patients on life support compared with other patients [29]. The Italian urgent lung transplant programme was introduced in November 2010, giving a national priority to patients $\leqslant 50$ years old requiring mechanical ventilation and/or extracorporeal lung support. Results from the first 14 months showed 30-day, 6-month and 1-year survival rates of $82 \%$, $76 \%$ and $71 \%$, respectively, and a mortality rate on the urgent waiting list of $11 \%$, while another $11 \%$ of the patients were excluded because of worsening conditions [10]. The Super-Urgent and Urgent Lung Allocation Schemes were introduced in the UK in 2017, in order to give a national priority to patients who are at most risk of dying on the waiting list [30]. Criteria for Super-Urgent Lung Allocation Scheme registration include extracorporeal life support with ECMO or interventional lung assist (Novalung), while criteria for Urgent Lung Allocation Scheme registration depend on the underlying disease [31]. The 2018 Annual Report on Cardiothoracic Organ Transplantation in the UK showed that there were 33 urgent lung registrations and seven super-urgent lung registrations between April 2017 and March 2018 [32]. Results after the implementation of this new allocation system in the UK have not yet been reported. Taken together, these data suggest that HELT and other gravity-based urgent allocation systems are associated with suboptimal outcome. Given that the whole allocation system is not destabilised, this might be an acceptable trade-off for minimising waiting list mortality.

Conversely, the LAS has been designed to maximise the benefits of transplantation, and therefore allocates lungs based on both urgency and transplant benefit. The implementation of the LAS in the USA has been reported to be associated with fewer waiting list deaths, more transplants performed, a change in the distribution of recipient diagnoses to patients more likely to die on the waiting list and an improvement in 1-year survival [6]. However, the LAS has been designed in the USA and does not take into account two urgent status parameters, i.e. extracorporeal support and mechanical ventilation. Its applicability to other transplant populations and to the most severe patients was therefore questionable. The impact of the LAS in urgent and highly urgent lung transplantation candidates was assessed in 2011 in Eurotransplant (Austria, Belgium, Croatia, Germany, Hungary, the Netherlands, Luxembourg and Slovenia). SMITs et al. [28] showed that the LAS and the LASplus (encompassing extracorporeal support and noninvasive ventilation) were significantly associated with 1-year post-transplant mortality and overall mortality. Since then, Germany was the first European country to adopt the LAS in 2011, followed by the Netherlands in 2014. As 
patients on mechanical ventilation or extracorporeal support were not accounted for in the LAS, specific allocation rules were introduced in Eurotransplant, as well as proposing an exceptional LAS when the calculated LAS does not reflect the transplant benefit for a particular patient [33]. Since the introduction of the LAS, the German experience reported a $26 \%$ decrease in waiting list mortality and an improved 1-year survival rate from $76 \%$ (2009-2011) to $81 \%(2012-2014)$ [34], suggesting that the benefits associated with the LAS could be applicable outside the USA and in very severe patients.

\section{Limitations}

Our study has several limitations. The number of covariates (mean pulmonary arterial pressure, pre-operative cardiopulmonary support and graft ischaemic time) with $>10 \%$ of missing data could bias the results. We tried to take these into account by using a multiple imputation method by chain equations. We also included recipient, donor and surgical characteristics as potential cofounding factors in the multivariate analysis. Still, we cannot exclude that other factors not studied in our analysis or unidentified may have biased our results. Our survival rates are somewhat lower than those reported in the International Thoracic Organ Transplant (TTX) Registry (https://ishlt.org/registries/ttx-registry), but represent real-life data as depicted in an exhaustive administrative database that does not include COPD patients.

\section{Conclusions}

This exhaustive French national study suggests that the adverse outcome associated with the HELT procedure is related to the severity status of the recipients rather than donor or matching characteristics.

Acknowledgements: Lung transplant working groups of the Société Française de Chirurgie Thoracique et Cardiovasculaire (SFCTCV), Société de Pneumologie de Langue Française (SPLF) and Agence de la Biomédecine $(\mathrm{ABM})$

Conflict of interest: None declared.

\section{References}

1 De Meester J, Smits JM, Persijn GG, et al. Lung transplant waiting list: differential outcome of type of end-stage lung disease, one year after registration. J Heart Lung Transplant 1999; 18: 563-571.

2 Valapour M, Skeans MA, Heubner BM, et al. OPTN/SRTR 2013 annual data report: lung. Am J Transplant 2015; 15: Suppl. 2, 1-28.

3 Reeb J, Keshavjee S, Cypel M. Expanding the lung donor pool: advancements and emerging pathways. Curr Opin Organ Transplant 2015; 20: 498-505.

4 Bhorade SM, Vigneswaran W, McCabe MA, et al. Liberalization of donor criteria may expand the donor pool without adverse consequence in lung transplantation. J Heart Lung Transplant 2000; 19: 1199-1204.

5 Cypel M, Yeung JC, Liu M, et al. Normothermic ex vivo lung perfusion in clinical lung transplantation. $N$ Engl $J$ Med 2011; 364: 1431-1440.

6 Egan TM, Edwards LB. Effect of the lung allocation score on lung transplantation in the United States. $J$ Heart Lung Transplant 2016; 35: 433-439.

7 Maxwell BG, Levitt JE, Goldstein BA, et al. Impact of the lung allocation score on survival beyond 1 year. Am J Transplant 2014; 14: 2288-2294.

8 Thabut G, Christie JD, Mal H, et al. Survival benefit of lung transplant for cystic fibrosis since lung allocation score implementation. Am J Respir Crit Care Med 2013; 187: 1335-1340.

9 Boussaud V, Mal H, Trinquart L, et al. One-year experience with high-emergency lung transplantation in France. Transplantation 2012; 93: 1058-1063.

10 Boffini M, Venuta F, Rea F, et al. Urgent lung transplant programme in Italy: analysis of the first 14 months. Interact Cardiovasc Thorac Surg 2014; 19: 795-800.

11 Agence de la Biomédecine. Greffe cardio-pulmonaire et pulmonaire. [Cardiopulmonary and pulmonary transplant.] 2013. www.agence-biomedecine.fr/annexes/bilan2013/donnees/organes/04-coeur-poumon/pdf/pcp.pdf Date last accessed: August 2, 2019.

12 Barnard JB, Davies O, Curry P, et al. Size matching in lung transplantation: an evidence-based review. J Heart Lung Transplant 2013; 32: 849-860.

13 Therneau TM, Grambsch PM. Modeling Survival Data: Extending the Cox Model. New York, Springer, 2000.

14 Grambsch PM, Therneau TM. Proportional hazards tests and diagnostics based on weighted residuals. Biometrika 1994; 81: 515-526.

15 Thabut G, Mal H, Castier Y, et al. Survival benefit of lung transplantation for patients with idiopathic pulmonary fibrosis. J Thorac Cardiovasc Surg 2003; 126: 469-475.

16 Orsini B, Sage E, Olland A, et al. High-emergency waiting list for lung transplantation: early results of a nation-based study. Eur J Cardiothorac Surg 2014; 46: 41-47.

17 Roux A, Beaumont-Azuar L, Hamid AM, et al. High Emergency Lung Transplantation: dramatic decrease of waiting list death rate without relevant higher post-transplant mortality. Transpl Int 2015; 28: 1092-1101.

18 Savale L, Le Pavec J, Mercier O, et al. Impact of high-priority allocation on lung and heart-lung transplantation for pulmonary hypertension. Ann Thorac Surg 2017; 104: 404-411.

19 Agence de la Biomédecine. Le rapport médical et scientifique du prélèvement et de la greffe en France. [The medical and scientific report of sampling and transplantation in France.] 2017. www.agence-biomedecine.fr/ annexes/bilan2017/donnees/organes/04-coeur-poumon/synthese.htm Date last accessed: August 2, 2019. 
Riou J, Boëlle PY, Christie JD, et al. High emergency organ allocation rule in lung transplantation: a simulation study. ERJ Open Res 2017; 3: 00020-2017.

21 Moreno P, Alvarez A, Santos F, et al. Extended recipients but not extended donors are associated with poor outcomes following lung transplantation. Eur J Cardiothrac Surg 2014; 45: 1040-1047.

22 Taghavi S, Jayarajan SN, Furuya Y, et al. Examining ABO compatible donors in double lung transplants during the era of lung allocation score. Ann Thorac Surg 2014; 98: 1167-1174.

23 Eberlein M, Reed RM, Bolukbas S, et al. Lung size mismatch and primary graft dysfunction after bilateral lung transplantation. J Heart Lung Transplant 2015; 34: 233-240.

24 Ganapathi AM, Mulvihill MS, Englum BR, et al. Transplant size mismatch in restrictive lung disease. Transplant Int 2017; 30: 378-387.

25 Eberlein M, Arnaoutakis GJ, Yarmus L, et al. The effect of lung size mismatch on complications and resource utilization after bilateral lung transplantation. J Heart Lung Transplant 2012; 31: 492-500.

26 Orens JB, Boehler A, de Perrot M, et al. A review of lung transplant donor acceptability criteria. J Heart Lung Transplant 2003; 22: 1183-1200.

27 Egan TM. How should lungs be allocated for transplant? Semin Respir Crit Care Med 2018; 39: $126-137$.

28 Smits JM, Nossent GD, de Vries E, et al. Evaluation of the lung allocation score in highly urgent and urgent lung transplant candidates in Eurotransplant. J Heart Lung Transplant 2011; 30: 22-28.

29 Auråen H, Schultz HHL, Hämmäinen P, et al. Urgent lung allocation system in the Scandiatransplant countries. J Heart Lung Transplant 2018; 37: 1403-1409.

30 Kourliouros A, Hogg R, Mehew J, et al. Patient outcomes from time of listing for lung transplantation in the UK: are there disease-specific differences? Thorax 2019; 74: 60-68.

31 NHS Blood and Transplant. Lung Candidate Selection Policy. 2018. https://nhsbtdbe.blob.core.windows.net/ umbraco-assets-corp/10834/pol231_3-lung-selection-policy.pdf Date last accessed: August 2, 2019.

32 NHS Blood and Transplant. Annual Report on Cardiothoracic Organ Transplantation. 2018. https://nhsbtdbe.blob. core.windows.net/umbraco-assets-corp/12636/

nhsbt-cardiothoracic-organ-transplantation-annual-report-2017-2018.pdf Date last accessed: August 2, 2019.

33 Smits JM, Nossent G, Evrard P, et al. Lung allocation score: the Eurotransplant model versus the revised US model - a cross-sectional study. Transpl Int 2018; 31: 930-937.

34 Gottlieb J, Smits J, Schramm R, et al. Lung transplantation in Germany since the introduction of the lung allocation score. Dtsch Arztebl Int 2017; 114: 179-185. 